\title{
ENGLISH PREFIXATION-A TYPOLOGICAL SHIFT?
}

\author{
LAURIE BAUER
}

\begin{abstract}
In Old English, as in modern Dutch and German, there were a series of prefixes which were unstressed and phonologically constrained; some of them, because they determined the wordclass of the derivatives they formed, were typologically unusual. If we trace these prefixes through into modern English, we find that they have lost ground. Partly they have been replaced by corresponding learned prefixes, partly they have simply become marginalised in the system of English. At the same time, if we look at those prefix-like items which are most productive today, we see that they carry their own stress, are phonologically unconstrained, and many of them are semantically much more lexeme-like. We can interpret these observations as a shift from a largely compounding Germanic basis through a long period of English history where prefixes were a norm, and with signs now starting to appear that a return to a more compound-oriented stage of the language is under way. In retrospect, we have no difficulty in explaining the various shifts of type that have occurred. What is interesting is the method by which the compound-orientation is being re-established, and the possible effect of typological pressures on such a shift.

The more compound-oriented modern stage is being achieved not through any simple change, but through a conspiracy of different changes which have the combined effect of leaving erstwhile prefixal elements looking more like lexemes. The changes can be seen as being influenced by the pressures which give rise to the so-called suffixing preference across languages: replacing prefixes with lexemes increases the number of items to be recognised by the listener, but allows maximal use of word-initial cues.
\end{abstract}

If we look at prefixation in West Germanic languages like Dutch and German, we find we must distinguish between native and non-native prefixes (the latter being those forms like anti-, bi-, mono-, pre-, which come from Greek and Latin), and within the native prefixes between those which are homophonous with a prepositional adverb (and where formations involving them might be considered to be compounds) and those which can be analysed only as prefixes. This last type are unstressed, prefer the vowel [ə], permit only coronal consonants (mainly sonorants) in coda position, and when used in the formation of verbs, block the prefixation of the past-participle ge-prefix. I will provisionally call these 'true' prefixes. 
(1) Dutch German

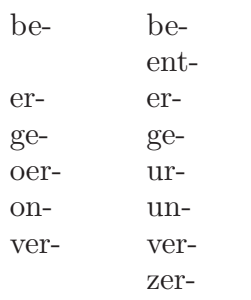

Dutch and German also have a set of prefixes derived from lexemes by a process of semantic bleaching: German haupt-and Dutch oud- for instance. The situation in Old English was not dissimilar to that in Dutch and German: the set of true prefixes appears to have been smaller, and not always the same set as is found in Dutch and German, but the fundamentals of the system are similar (Kastovsky 1992, 377ff).

If we trace the true prefixes of English through to present-day English, we discover that they have been greatly eroded.

The prefix $a$ - as in ablaze, deriving adjectives from (mainly) verbs, had a peak of productivity in the nineteenth century (Marchand 1969, 140) and is still marginally productive as witness the forms awhir, aclutter and others in Barnhart et al. (1973), but these are rather self-conscious formations these days.

The verbalising prefix $b e$ - is these days stylistically and formally restricted, as the example below indicates, where the $b e$ - arises in conjunction with a denominal -ed and where there is a light-hearted feel to the derivatives.

(2) "A multiplicity of chins rested upon his befairisled chest. The bepatched elbows of his shirt rested upon the bepatched knees of his corduroy trews." (Rankin 1994, 36f)

The prefix mis-, which was used in Old English, became contaminated with French més- and gained extra life from that (Marchand 1969, 176f). It was still marginally productive in the twentieth century.

Marchand $(1969,200)$ gives a brief discussion of the prefix twi-, which he says is now restricted to literary use. This literary use in the nineteenth century and the early years of the twentieth is illustrated in The Oxford English Dictionary, but I think it has now died out.

The prefix un- remains extremely productive, especially when added to adjectives.

Kastovsky (1992) also lists $x f_{-}, e d-$, ge-, or-, op-, sam-, sin-, wan- as Old English prefixes and these are not even mentioned by Marchand (1969). 
The prefix en-, which might look as though it belongs to this set, is of French origin (from Latin in-), and is not relevant in this context.

Basically, with the notable exception of un-, we have seen a whole class of prefixes vanish in English. Where they have not completely vanished, they have generally been so cut back in productivity as to form very weak patterns, and we can predict that they are likely to die out before very long. This disappearance has, of course, not happened without a corresponding increase in other kinds of left-adjoined obligatorily bound forms. If we consider a list of such elements used in a couple of recent dictionaries of English neologisms, we find that those that are being used are very different indeed.

$\begin{array}{llll}\text { a- } & \text { electro- } & \text { multi- } & \text { quadra- } \\ \text { agri- } & \text { Euro- } & \text { nano- } & \text { re- } \\ \text { anti- } & \text { giga- } & \text { narco- } & \text { retro- } \\ \text { audio- } & \text { hyper- } & \text { neo- } & \text { sub- } \\ \text { bio- } & \text { immuno- } & \text { non- } & \text { super- } \\ \text { chloro- } & \text { info- } & \text { para- } & \text { techno- } \\ \text { contra- } & \text { kilo- } & \text { petro- } & \text { tele- } \\ \text { counter- } & \text { macro- } & \text { post- } & \text { tera- } \\ \text { cryo- } & \text { mega- } & \text { pre- } & \text { un- } \\ \text { de- } & \text { micro- } & \text { pro- } & \text { under- } \\ \text { dis- } & \text { midi- } & \text { pseudo- } & \text { uni- } \\ \text { eco- } & \text { mini- } & \text { psycho- } & \end{array}$

There are a number of points to be made about this list.

- Most of these are non-native (un- and under- stand out as exceptions). French, Latin and Greek vie to provide English prefixal elements these days. Even an element like info- is clipped to give it a Greek-looking form.

- Although a large number of Romance prefixes became transferred to English as a result of the post-Norman-Conquest spate of French loans, and although many of these (de-, dis-, re-) remain productive in presentday English, they do not provide the heart of the system that might be expected.

- The new prefixed elements contain full vowels. Even prefixes like re- and pre- in productive use are pronounced with a full vowel $(/ \mathrm{ri} / /, / \mathrm{pri} /)$ and their own stress (contrast redo with a lexicalised refer or prepay with a lexicalised prepare). These prefixed elements are also overwhelmingly disyllabic. Rephrasing that we may say that they have the phonological structure of lexemes rather than that of affixes. While not every phoneme of English is attested in the list given above, it is not clear that there is 
any restriction in operation here, as opposed to accidental gaps caused by the fact that e.g., /or/ is a rare phoneme of English.

- If we look at these productive prefixal elements from a semantic point of view, we can see that we have moved away from purely grammatical meanings (like transitive verbaliser, negative) and even from the fundamental prepositional meanings (though there are still many of those: post-, pre-, pro-) to meanings which are equivalent to (because derived from) the meanings of lexemes (consider audio-, chloro-, kilo- and petro-).

It is easy in English to co-ordinate adjectives: red and white wines, for instance. It is also easy to co-ordinate certain nominal premodifiers: brick and stone walls. This pattern of co-ordination seems to extend into items which are written as compounds: gold- or coal-mining (attested: WCWNZE J02 $169)$ is fine, although Quirk et al. $(1985,971)$ claim that tooth-and headaches is not. From the data just presented, it might appear that what is permitted has in some way to do with the independence of the modifier as a word in its own right. This is only true to a certain extent. Investigations by Booij (1985), Okada (1999) and Smith (2000) indicate that in Dutch, German and English what is permissible in such constructions is largely dependent upon the phonological structure of the elements superficially co-ordinated and that of the head element. (Note that strictly speaking the superficially coordinated elements in an expression such as pre- and post-conceptional counseling, from FROWN [H10 087], are not immediate constituents and thus rather odd coordinates.) Specifically, anything which is to end up looking as though it is co-ordinated must have the phonological structure of a word (and sometimes the phonological structure of one element has to be modified to allow this to happen). The reason this is relevant in the context of this paper is that some prefixes can arise in such constructions. Quirk et al. (1985, 970) cite ante- and post-natal, pro- and anti-establishment, sub- and super-human. Not all prefixes can freely occur in this construction, though: *im- and exports is ruled out by Quirk et al. (ibid.) though there are several possible reasons for the exclusion of this particular example. Even un- or malformed foetuses seems marginal, and Stein (2002) suggests that only polarised prefixes can occur in this type of construction. One of the striking things about the list of currently productive prefixes is that they virtually all have an appropriate phonological structure to allow them to participate in this construction (they may, of course, be prevented for semantic reasons, but that is a separate matter). Prefixes like $b e-$, which are in the process of vanishing, do not have this structure. One result of this is thus that prefixal elements are looking more and more like phonological words. Sometimes some of these elements even look 
as though they are more than simply phonologically word-like, in that they end up in a construction co-ordinated with a real word: para- and alternative medics (WCWNZE J47 159), fore- and mainmasts (WCWNZE K17 044).

Further, some of these prefixal elements are starting to show a greater level of independence by becoming clippings or free words: anti, mini, pro, sub, super. Note that while words like anti and pro are turning into free prepositional adverbs, other examples are becoming nouns, a distinction largely controlled by the semantics of the element concerned and the method of word-formation (clippings retain the part of speech of the long base form). Similar developments can be observed with a number of Graeco-Latinate elements which are becoming used as free words: amnio, audio, hyper, micro, macro, photo, tele (usually spelt telly).

What these things have in common is a move away from the obligatorily bound status of prefixes towards a situation where the elements which are added to the left-hand edge of English words are in themselves more wordlike. This can be seen as a movement away from prefixation and towards something more like compounding. Note, however, that this is not simply a rejection of boundedness; it is a gradual not an abrupt shift, perhaps a conspiracy (in Kisseberth's 1970 terms).

Interestingly, the situation we appear to be heading towards is not new. Nearly all of the true prefixes in Dutch or German had their origins in free forms (Priebsch-Collinson 1962, 253ff), and in Old English some prefixes had stressed and unstressed forms, and the relationship between the two may or may not have been obvious to speakers of the language (Lass 1994, 203ff). Thus we have evidence for nearly a full cycle: a cycle from compounding through to prefixation (through loss of stress and phonetic erosion) and back to something which is starting to look again more like compounding. We can even give a post-hoc rationalisation of why these changes should have taken place. The change from compounding to prefixation takes place, as I just observed, for phonetic reasons, with elements in unstressed position maintaining neither their vowel qualities nor the full range of consonant distinctions. The change from prefixation to compounding can be justified on the basis that this second pattern has always been present: in German the prepositional adverbs such as an, auf, aus, mit, nach etc. have always been used as prefixes, and in English, too, elements like in-, over- and with- (this last no longer productive, but analysable in words like withhold, withstand) mean that the pattern has always been available - and not only available but phonologically and semantically transparent, regular and type- and token frequent, all factors which might be expected to lead to productivity of the pattern. The 
fact of the re-emergence of an ancient pattern is thus perhaps explicable in language-specific terms. The way in which the ancient pattern is re-emerging is, it seems to me, of some independent interest.

The new pattern is emerging through a conspiracy: the failure of the stressless native true prefixes to remain productive, the gradual lexicalisation of prefixes from Romance, and the use of obligatorily bound stems as if they were part of the dominating word-based morphology.

Because compounding is so important in English and other Germanic languages, a pull towards a compounding type may be expected. This would lead to the prediction that similar tendencies in Romance languages would be far less strong, Romance generally having less compounding than Germanic. Clearly English has never got very far down the prefixation route (although seventeenth century English would have looked far more like that than modern English does). Having seen the shift in English, the open question is whether this has implications for other things. One possibility is that this is linked to the suffixing preference (Cutler et al. 1985). Cutler et al. point out that there are some types of category which seem to prefer suffixal marking crosslinguistically. One of these is valency marking. The prefix in a word like bemoan is precisely a valency marker, and is thus a counter-example to the universally unmarked pattern. We would not expect this in itself to cause a change in the word-formation patterns of an individual language, unless there were strong processing reasons for the original observation. Cutler et al. argue that this has to do with the importance of word-beginnings for wordperception. Since true prefixes mask the beginnings of words, they should, according to this view, hinder perception (though note that this observation should hold true only with productive prefixes which have to be analysed on-line). Replacing prefixes with words increases the number of items to be perceived, but should facilitate that perception.

We might speculate that due to phonetic erosion, English was placed in a position where it had prefixes, and was thus free to borrow more prefixes from Romance, Greek and Latin in a relatively unconstrained manner. It is now reverting to type, and losing its prefixes again in favour of a greater density of things that look like compounds. Whether this is actually a typological difference, along the lines of the factors discussed by Kastovsky (e.g., 2000), is something which could be discussed. It is not a parameter which Kastovsky lists, but a change from obligatorily bound affixes to combinations of potentially free items looks like a change from synthesis towards analysis, and so seeing this as a potential typological shift does not seem too much to claim. It remains to be seen, of course, what changes to English might result from 
a change of type of this nature, if any. What may be more relevant in the short term is that this tendency in English may illustrate a diachronic process which strengthens the suffixing preference, and thus provides the kind of linkage between synchronic patterns and diachronic processes which is sought by Hall (1992).

\section{Corpora}

FROWN. The Freiburg-Brown Corpus of American English. See HTtP://WWW.hit.uib.no/ICAME/Frown/INDEX.hTM

WCWNZE. The Wellington Corpus of Written New Zealand English.

See HTTP://KHNT.HIT.UiB.No/ICAME/MANUALS/WELLMAN/INDEX.HTM

\section{References}

Barnhart, Clarence L. - Sol Steinmetz-Robert K. Barnhart 1973. The Barnhart dictionary of New English 1963-1972. Longman, London.

Booij, Geert E. 1985. Coordination reduction in complex words: a case for prosodic phonology. In: Harry van der Hulst - Norval Smith (eds) Advances in nonlinear phonology, 143-60. Foris, Dordrecht.

Cutler, Anne-John A. Hawkins - Gary Gilligan 1985. The suffixing preference: a processing explanation. In: Linguistics $23: 723-58$.

Hall, Christopher J. 1992. Morphology and mind. Routledge, London.

Kastovsky, Dieter 1992. Semantics and vocabulary. In: Richard M. Hogg (ed.) The Cambridge history of the English language. Volume 1: The beginnings to 1066, 290-408. Cambridge University Press, Cambridge.

Kastovsky, Dieter 2000. English morphology: a typological reappraisal. In: Chris SchanerWolles - John Rennison - Friederich Neubarth (eds) Naturally!, 215-24. Rosenberg and Sellier, Turin.

Kisseberth, Charles W. 1970. On the functional unity of phonological rules. In: Linguistic Inquiry $1: 291-306$.

Lass, Roger 1994. Old English. Cambridge University Press, Cambridge.

Marchand, Hans 1969. The categories and types of present-day English word-formation (Second edition). Beck, Munich.

Okada, Sadayuki 1999. On the conjoinability of affixal morphemes in English. In: Word 50: 339-63.

Priebsch, R.-W.E. Collinson 1962. The German language (Fifth edition). Faber and Faber, London.

Quirk, Randolph - Sidney Greenbaum-Geoffrey Leech-Jan Svartvik 1985. A comprehensive grammar of the English language. Longman, London. 
Rankin, Robert 1994. Raiders of the lost car park. Corgi, London.

Smith, George 2000. Word remnants and co-ordination. In: Rolf Thieroff-Matthias TamratNanna Furhop - Oliver Teuber (eds) Deutsche Grammatik in Theorie und Praxis, 57-68. Niemeyer, Tübingen.

Stein, Gabriele 2002. The word and its inseparability. In: Sybil Scholtz-Monika Klages-Evelyn Hantson- Ute Römer (eds) Language: context and cognition, 289-99. LangenscheidtLongman, München.

Address of the author: Laurie Bauer

School of Linguistics and Applied Language Studies

Victoria University of Wellington

PO Box 600

Wellington

New Zealand

laurie.bauer@vuw.ac.nz 